IDEAS, TEORIAAS, PROBLEMAS

\title{
La memoria, la Diosa Madre y los ídolos placa de la Iberia neolítica
}

Katina T. Lillios, Department of Anthropology, University of lowa

Traducción: Leonardo García Sanjuán

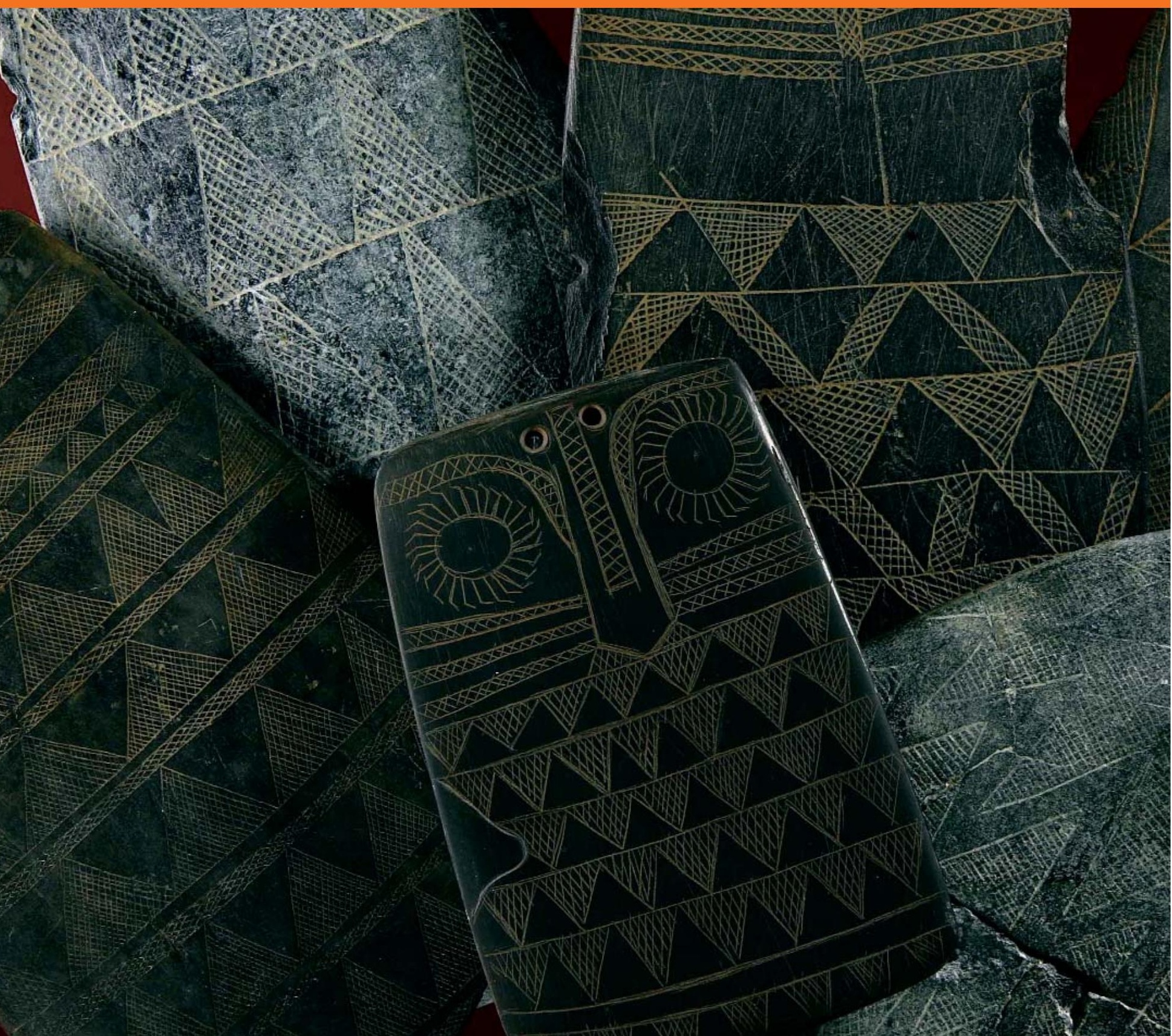




\section{INTRODUCCIÓN}

Descubiertas por centenares en cuevas, abrigos rocosos y megalitos del Neolítico y la Edad del Cobre, las placas de piedra grabadas (conocidas cómo "ídolos placa" en la literatura española) han disfrutado de un lugar preferente en la imaginación de los arqueólogos desde el siglo XIX (imagen 1). Los prehistoriadores han sugerido que las placas, hechas principalmente en pizarra y de unos $15 \mathrm{~cm}$ de longitud máxima de promedio, funcionaban como amuletos, ídolos o insignias y que sus motivos representaban a los muertos o las divinidades, incluyendo a la Diosa Madre europea. Otros objetos portables encontrados en enterramientos de esta cronología de la Península Ibérica, tales como "ídolos oculados" de hueso o piedra tallada, han sido también interpretados como representaciones de la Diosa Madre. Para muchos, muy especialmente Marija Gimbutas (1921-1994), todos estos objetos eran manifestaciones del culto a la Diosa Madre, que se habría originado en el Próximo Oriente y que estuvo asociado a la expansión de la agricultura por Europa por parte de unas sociedades igualitarias, pacíficas y ginocéntricas.

Aunque muchos arqueólogos han afirmado que la sociedad neolítica europea no fue ni igualitaria ni pacífica y que no hay evidencias para proponer que fuera particularmente ginocéntrica, la idea de un culto a la Diosa Madre sigue sin embargo vigente en las formas específicas en que se interpreta el arte mueble del Neolítico de la Península Ibérica. No obstante, esta interpretación presenta algunos problemas. En relación con las placas ibéricas, por ejemplo, muy pocas muestran elementos que puedan ser considerados antropomórficos, y hay poco que indique de forma no ambigua que representan ideas de feminidad o divinidad. Incluso en el caso de las figurillas de hueso de Andalucía que son más claramente antropomórficas, algunas presentan genitales masculinos.
Dada su abundancia (por encima de 2000) y amplia distribución (desde Leiria, en Portugal, hasta Granada, en España), su variabilidad en cuanto a diseños y formas y el arco temporal en el que fueron utilizadas (500-1000 años) es improbable que haya un único modelo que pueda explicar el fenómeno de las placas grabadas (o del arte portable neolítico en general).

En este ensayo voy a proporcionar algo de información básica sobre las placas grabadas, resumiendo el resultado de una investigación reciente que está más ampliamente desarrollado en mi libro Heraldry for the Dead: Memory, Identity, and the Engraved Stone Plaques of Neolithic Iberia, basado en un catálogo en línea exhaustivo de las placas Ilamado ESPRIT (Engraved Stone Plaque Registry and Inquiry Tool, http://research2.its.uiowa.edu/iberian/index.php). Mi análisis de la distribución geográfica y forma de las placas sugiere que la mayoría de ellas (las Ilamadas "placas clásicas") registraban la filiación genealógica y de linaje de individuos de élite en el suroeste de Iberia. En otras palabras, pueden haber servido como una cierta forma de heráldica para una clase específica de difuntos ancestrales.

\section{CONTEXTOS}

Las placas fueron hechas y utilizadas durante el Neolítico Final de la Península Ibérica, periodo durante el cual emergieron las primeras comunidades asentadas y plenamente agrarias, entre 4000 y 3000 a.n.e. Muchas de esas comunidades ocuparon asentamientos fortificados que controlaban de forma estratégica cauces fluviales y valles fértiles. Durante este periodo, los muertos eran enterrados de forma colectiva en megalitos (incluyendo tholol), cuevas y abrigos rocosos. Las placas grabadas se han encontrado en más de 200 sitios funerarios de la esquina suroeste de la Península Ibérica, con la máxima concentración en el Alentejo portugués. 
3. Placa grabada de Olival da Pega 1 (Évora, Portugal) / Fuente: MUSEU NACIONAL DE ArqueOlogía, Portugal

4. Placa grabada de Valencina de la Concepción (Sevilla, España) / Foto: GUILLeRmo Mendo Murillo. Fuente: Junta de Andalucía. Museo AroueolóGico de SeVILla
No todas las personas eran enterradas con placas. Cuando se las encuentra con un esqueleto preservado, las placas aparecen individualmente sobre su pecho o al costado (imagen 2). Hasta la fecha, solo una o dos placas han sido encontradas en asociación con esqueletos cuyo sexo y edad en el momento de la muerte hayan podido ser diagnosticados de forma científica. Uno de los mayores desafíos a los que se enfrenta el estudio de las placas ibéricas es que no hay fechas absolutas para datarlas. Esto es debido a la reutilización (y alteración) de las tumbas colectivas, los suelos ácidos del Alentejo, donde la mayoría de las placas han sido encontradas, y al hecho de que una gran parte de ellas proceden de excavaciones antiguas (de finales del siglo XIX y comienzos del XX), cuando no era habitual realizar estudios antropológicos de los restos humanos.

\section{VARIABILIDAD EN LA FORMA Y DISTRIBUCIÓN GEOGRÁFICA}

Se han distinguido 8 tipos principales de placas a partir de la estructura compositiva, la forma, número de perforaciones, número de caras grabadas y motivos presentes, identificándolos como tipos I a VIII (imagen 5):
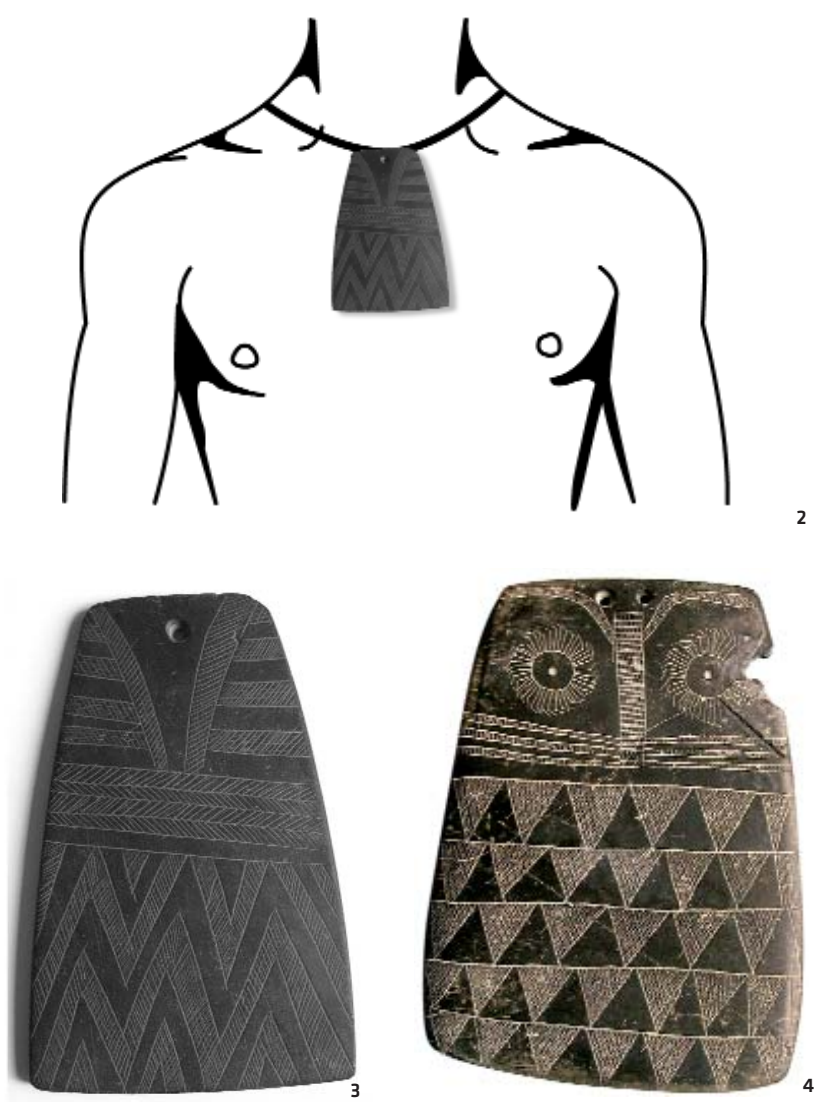

Tipo l: Clásico. Constituye el tipo de placa más abundante y ampliamente distribuido. Las placas clásicas tienen una estructura compositiva bipartita consistente en un tercio superior estrecho y dos tercios inferiores (base) más amplios (imagen 3). La parte superior tiene también un campo triangular vacío en el centro (a menudo con una perforación) y un conjunto limitado de motivos, tales como correas, uves invertidas o rayos. Separando las partes superior e inferior hay bien una única línea horizontal o bien una o varias bandas horizontales, que pueden aparecer sin decoración o decoradas con retícula, triángulos o algún otros motivo geométrico. Los elementos decorativos se concentran en la base, encontrándose uno o más de una serie de seis motivos geométricos repetitivos: ajedrezado, bandas verticales, triángulos, chevrons, espigas y zigzags. Más abajo se examinan las placas clásicas en mayor detalle.

Tipo II: Transicional. Las placas transicionales se caracterizan por motivos que llenan casi la totalidad de la placa, con la excepción del campo triangular próximo a la perforación. Al contrario que las placas clásicas, las transicionales no están claramente divididas en dos campos compositivos. Este tipo es el segundo más común y también aparece con una amplia distribución. Los motivos asociados con estas placas son triángulos, chevrons y zigzags.

Tipo IIl: Azada. Son raras, también de estructura transicional, pero de forma compuesta (o con hombros marcados), aparecen decoradas únicamente con triángulos.

Tipo IV: Unipartitas. Las placas unipartitas tienen motivos que cubren toda la cara de la placa, sin que ningún elemento formal separe la parte alta de la base. En estas placas se utilizan varios motivos distintos.

Tipo V: Alfombras. Estas placas tienen una composición distintiva (un campo cuadrado o rectangular rodeado por un ribete decorado) y están grabadas en las dos caras. Los motivos asemejan un textil o alfombra. Las placas alfombra están normalmente hechas en arenisca de color rosa, aunque algunas se manufacturaron en pizarra y esquisto. Estas placas son raras, y se las encuentra en la periferia de la región general por la que se distribuyen.

Tipo VI: Atirantadas. Estas placas son de forma compuesta, tienen dos perforaciones y presentan motivos en forma de tirantes y triángulos. Son asimismo bastante raras, y se las encuentra únicamente en el sector noreste del área general de distribución de las placas.

Tipo VII: Biomórfico simple. Estas placas (junto con las de Tipo VIII) son las que en gran medida alimentaron la interpretación de las placas como Diosa Madre. Las placas de tipo biomórfico simple muestran lo que parecen ser "apéndices" y a veces "ojos" o una "nariz". Son escasas 
VII. Leisner 1998 , tabla 75,2

VIII. Gonçalves 1992, fig. 28

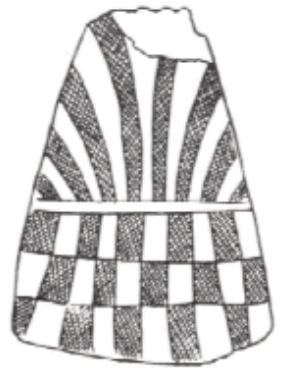

Tipo I: Clásico

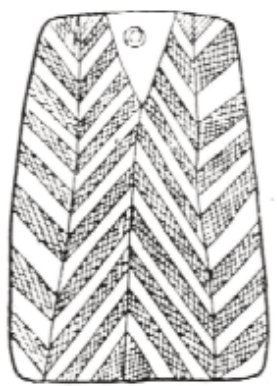

Tipo II: Transicional

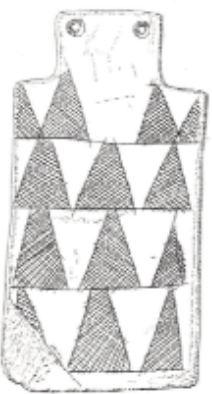

Tipo III: Azada

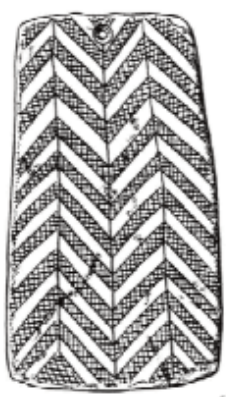

Tipo IV: Unipartitas
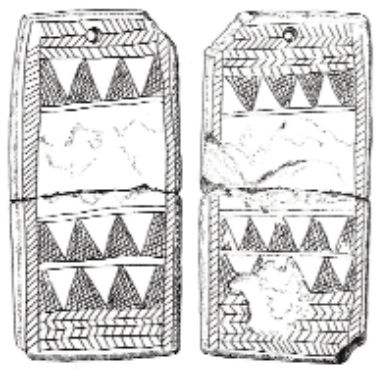

Tipo V: Alfombras

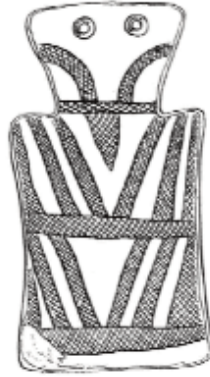

Tipo VI: Atirantadas
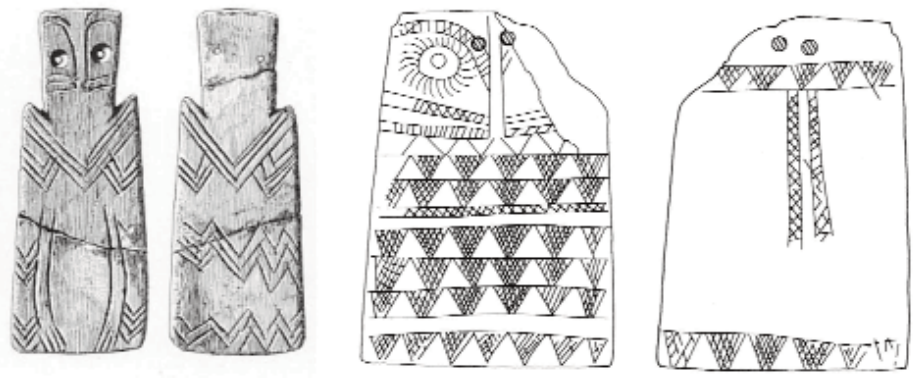

Tipo VII: Biomórfico simple Tipo VIII: Biomórfico whiskered y se las encuentra generalmente en el sector noreste del ámbito de distribución de las placas.

Tipo VIII: Biomórfico whiskered. Estas placas son similares y relacionadas a las de tipo biomórfico simple, aunque sus diseños incorporan más motivos geométricos (imagen 4 y 8). Tienen múltiples registros de triángulos (que a menudo aparecen invertidos) o chevrones en el anverso, 2 ó 3 bandas que irradian de la "nariz" (y que asemejan "bigotes" - whiskers) y "borlas" en el reverso. Son raras y aparecen fundamentalmente a lo largo de la periferia de del ámbito de distribución de las placas.

\section{LAS PLACAS CLÁSICAS}

Aunque las placas clásicas constituyen un tipo formal coherente, muestran un alto grado de variabilidad estilística y técnica. En algunas placas, por ejemplo, parece haber intentos de "comprimir" los registros. Estos registros "estrujados" presentan espaciados más pequeños y líneas con menor grado de rectitud, o fueron dibujados después que los otros registros (esto es lo que sugieren las diferentes técnicas o estilos de grabado).
En otras placas se encuentra la situación opuesta: aunque había espacio de sobra para crear registros adicionales, estos no se hicieron nunca. Hubo también algunas placas con bocetos preliminares en una cara, y un diseño completo o de aspecto más "finalizado" en la otra. Un ejemplo especialmente impactante de esto se encuentra en una placa del dolmen das Conchadas (Lisboa), que muestra un boceto inacabado con cuatro líneas horizontales sobre un lado, mientras que en el otro lado tiene el dibujado terminado de una placa clásica compuesta por tres líneas/registros horizontales (imagen 6). Finalmente, también hubo algunos autores de placas que rompieron con la norma de simetría, produciendo placas asimétricas y atípicas.

La naturaleza de esta variabilidad sugiere que el número de registros de las placas era un elemento clave en su diseño y que para sus creadores no era un elemento de importancia tan solo estética. Los registros parecen haber sido producidos de una forma altamente deliberada, y las placas fueron corregidas y revisadas para que finalmente contaran con el número deseado o correcto de ellos.

Si las placas clásicas eran sistemas de registro, ¿que podría entonces esperarse de su patrón de distribución espacial? En primer lugar, no espe- 

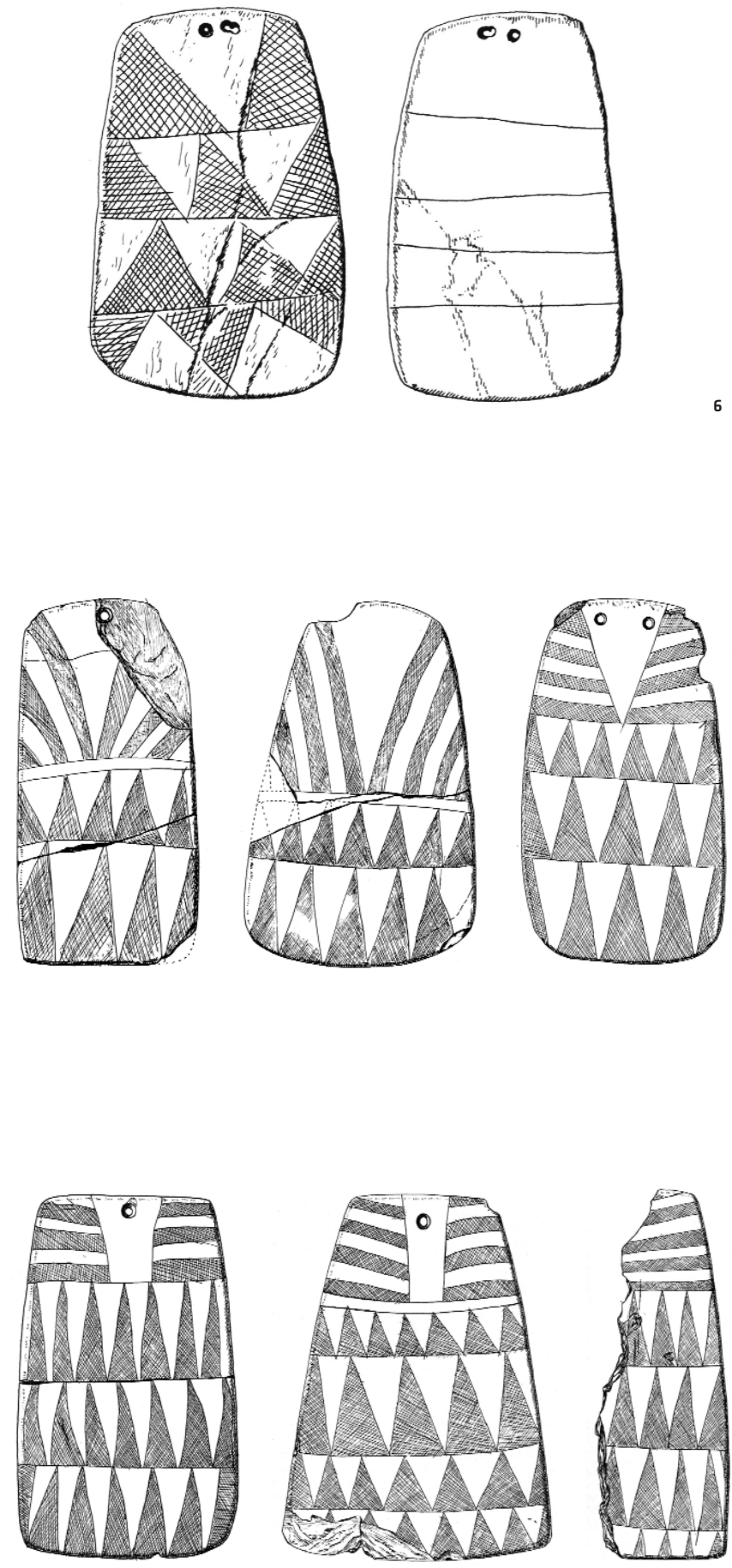

raríamos un patrón totalmente aleatorio. Y ciertamente, cuando comencé a analizar la dispersión espacial de las placas, aparecieron dos pautas intrigantes. Primero, la mayoría de ellas son encontradas como parte de secuencias de enterramiento. Es decir, las placas aparecen generalmente en secuencias, por motivos (como una secuencia de dos registros, tres, cuatro, cinco...). Aunque hay secuencias entre las placas clásicas con chevrones, zigzag y ajedrezados, estas continuidades son más recurrentes entre las placas clásicas con triángulos. En segundo lugar, la distribución de las placas por número de registros sugiere una dispersión con el número de registros aumentando de forma excéntrica desde su centro (y hacia el Oeste). Los sitios con número de registros bajos se encuentran en grupos relativamente pequeños hacia el Este, mientras que los sitios con placas provistas de un mayor número de registros aparecen por un área más grande más hacia el Oeste. En el caso de las placas con ajedrezados y triángulos, esta tendencia es especialmente fuerte. Este patrón distribucional refuerza la probabilidad de que las secuencias por número de registros no sean simplemente el resultado de una distribución estadísticamente aleatoria de las placas.

El abanico de datos (la evidencia cualitativa que suponen los bocetos, la continuidad de las secuencias de placas y la dispersión espacial de las mismas por registros) sugiere claramente que los registros de las placas clásicas contenía información de naturaleza secuencial y posiblemente acumulativa y/o cronológica. Es posible encontrar apoyo interno a la idea de que las placas pudieron denotar información secuencial en las idiosincrasias estilísticas de las placas, que han quedado codificadas en ESPRIT. Estas idiosincrasias, tales como la inclinación de los triángulos a la izquierda o a la derecha, han sido interpretadas como posibles marcadores de grabadores concretos. Las placas con los mismos tipos de idiosincrasias (y por lo tanto probablemente creadas por la misma mano) aparecen no sólo dentro de la misma tumba, sino que o bien tienen el mismo número de registros entre sí o bien difieren en uno o dos registros. Por ejemplo en el enterramiento de Granja de Céspedes (Badajoz), 6 de las 23 placas tienen triángulos inclinados (imagen 7), teniendo todas ellas dos, tres y cuatro registros.

\section{DISCUSIÓN}

Dado que cuando se las encuentra en asociación con un esqueleto preservado, las placas se sitúan sobre el pecho o el costado, parece desprenderse que las placas estaban estrechamente vinculadas a la identidad del muerto, o al menos de algunos de los muertos. Su contexto y asociación con los muer tos parece excluir su utilización como registro de tipo catastral, como parece ser el caso de las fichas mesopotámicas antiguas. La naturaleza colectiva de los enterramientos en el Neolítico Final y el hecho de que las tumbas fueran utilizadas en largos periodos de 


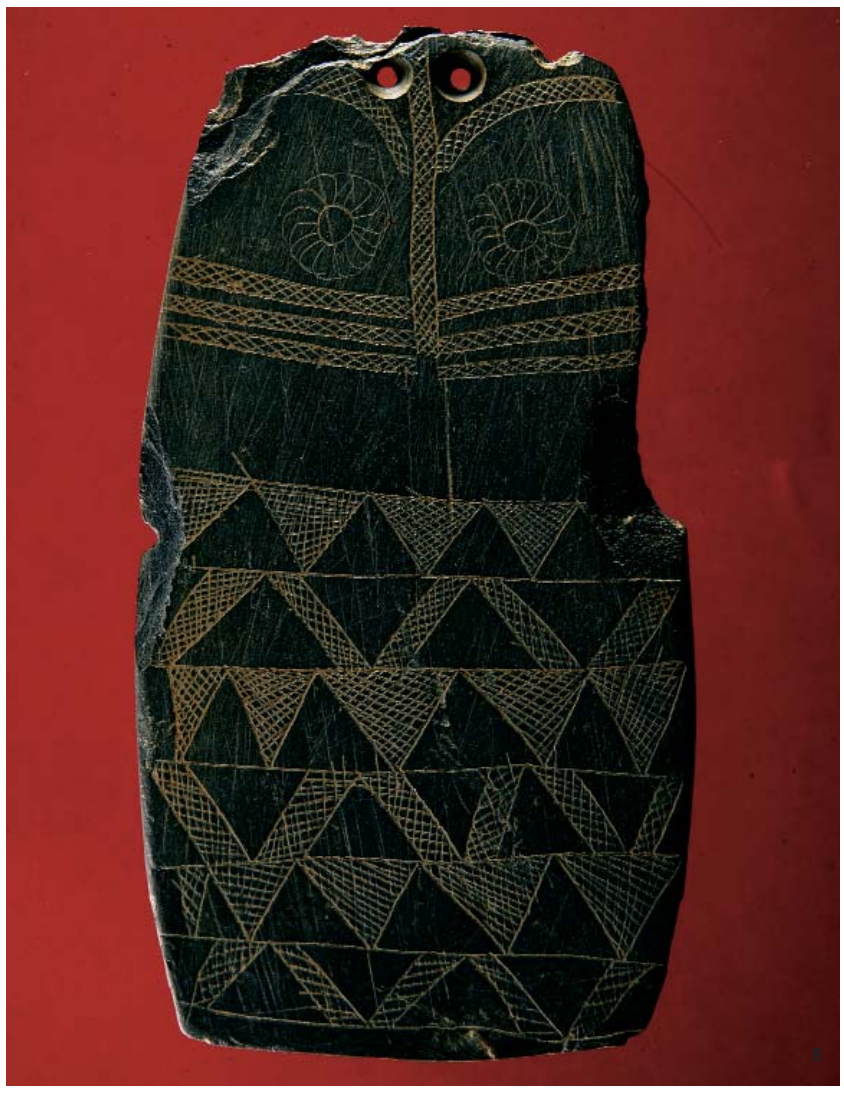

tiempo sugiere que los registros contenían información genealógica sobre los muertos. El modelo que propongo para las placas clásicas es que el número de registros contenía el número de generaciones que separaban al difunto de un ancestro importante o fundador. Este modelo es claramente una primera aproximación a lo que probablemente fue un sis- tema de registro más complejo, que esperamos pueda ser refinado y contrastado con estudios de ADN realizados sobre los restos esqueléticos encontrados en asociación con las placas grabadas. Dado que en general las placas aparecen en tumbas de corredor y cámara y otras tumbas abiertas, y por tanto eran visitadas periódicamente, parece razonable apuntar que, con independencia de su significado exacto, las placas eran concebidas para ser vistas y consultadas por gentes posteriores de cara a la toma de decisiones importantes, como por ejemplo quien tenía derecho a ser enterrado en la tumba.

¿Por qué semejantes y perdurables materializaciones de identidades sociales y genealogías habrían surgido únicamente en el Suroeste de Iberia? Yo he propuesto que la valiosa combinación de recursos de la región del Alentejo (concretamente los fértiles suelos, las vetas de cobre y los afloramientos rocosos de anfibolitas) fomentaron un ambiente de competición y ofrecieron oportunidades para que algunos grupos e individuos buscaran distinguirse y controlar el acceso al territorio o sus recursos. El fenómeno de las placas se vuelve más comprensible si se tiene en cuenta que los afloramientos de anfibolita y pizarra se encuentran a pocos kilómetros de distancia entre sí. La forma "en hacha" de las placas puede ser vista como una metáfora o evocación de poder que se asociaba con aquellos individuos o grupos involucrados en la producción y uso de hachas durante el Neolítico. Las Ilanuras abiertas del Alentejo habrían conformado un paisaje focal a través del cual se encontraban viajeros y comerciantes de distintas procedencias de la Península Ibérica, quizás hablando dialectos diferentes o mutuamente ininteligibles. Las tensiones y la competición por los valiosos recursos del Alentejo podrían haber estimulado la creación y materialización de identidades sociales, generando la producción de emblemas perdurables de esas identidades en forma de placas de pizarra grabadas.

\section{Bibliografía}

ALMAGRO BASCH, MARTíN (1961-1962) Un ajuar dolménico excepcional procedente de la Granja de Céspedes de Badajoz. En Homenaje a C. Mergelina. Murcia: Universidad de Murcia, 1961 1962, pp. 35-82

GONÇALVES, VICTOR S. (1992) Revendo as Antas de Reguengos de Monsaraz. Lisbon: Instituto Nacional de Investigação Científica, 1992
LEISNER, GEORG; LEISNER, VERA (1951) Antas do Concelho de Reguengos de Monsaraz. Lisbon: Uniarch, 1951

LEISNER, GEORG; LEISNER, VERA (1959) Die Megalithgräber der Iberischen Halbinsel. Der Westen. Berlin: Walter de Gruyter 1959

LEISNER, VERA (1965) Die Megalithgräber der Iberischen Halbinsel. Der Westen. Berlin: Walter de Gruyter, 1965
LEISNER, VERA (1998) Die Megalithgraber der Iberischen Halbinsel: Der Westen. Madrider Forschungen. Berlin: Walter de Gruyter, 1998, vol. I, 4

LILUIOS, KATINA T. (en prensa) Heraldry for the Dead: Memory, Identity, and the Engraved Stone Plaques of Neolithic Iberia Austin: University of Texas Press, 2008 